\title{
Artigo
}

Resumo

Este trabalho se propõe a pensar a clínica do acompanhamento terapêutico como uma modalidade de apoio à inclusão escolar a partir de uma formulação sobre o (não) saber do acompanhante terapêutico que trabalha na escola orientado pela psicanálise. Através de vinhetas clinicas, abordaremos três atores - os educadores, os especialistas e, finalmente, o acompanhante terapêutico - e seus discursos que circulam no universo da inclusão escolar.

Descritores: educação inclusiva; psicanálise; educação; acompanhamento terapêutico; saber.

\section{SABE-SE SOBRE A CRIANÇA? ACOMPANHAMENTO TERAPÊUTICO E EDUCAÇÃO INCLUSIVA}

Lenara Spedo Spagnuolo

DOI: http//dx.doi.ors/10.11606/issn. 1981-1624.v22i2p283-298.

$\mathbb{N}_{\text {a }}$ ão é nenhuma novidade entre os que trabalham com educação que o animal humano aprende. Antes de aprender a escrever, a contar ou a memorizar as capitais dos seu país, ele aprende a ser humano. A precariedade do nosso instinto faz com que apareça a supremacia da cultura em nossas vidas. Em outras palavras, é justamente porque o instinto humano falha - diferente do de outros animais - que a linguagem e a cultura se colocam como condição para o tornar-se humano.

Desse modo, nesse vazio dos instintos, se faz necessária a instalação da educação, que não pode vir de outro lugar senão do campo do Outro. É, portanto, sobretudo durante a infância que ocorrerá um processo de marcação no psiquismo da criança, de modo a torná-la familiar ao entrar no mundo. Isso é

- Psicóloga. Acompanhante terapêutica. Mestranda na Faculdade de Educação da Universidade de São Paulo (FEUSP), São Paulo, SP, Brasil. 
o que neste trabalho chamamos de educação: o inevitável processo de tornar-se humano. Processo, segundo Arendt (2011), inevitável enquanto novas pessoas continuarem a nascer: "a essência da educação é a natalidade, o fato de que seres nascem para o mundo" (p. 223), sendo assim, não há uma sociedade que opte por não educar suas crianças. A diferença geracional é fato necessário e suficiente para que haja educação. Ao nascer, o bebê entra na vida, mas não está no mundo. Essa entrada no mundo só pode ser feita pelo antigo, isto é, por aquilo que é anterior à criança: a cultura, a linguagem.

Freud, ao longo de sua obra, não se deteve explicitamente sobre o tema da educação, embora tenha se interessado pelo assunto e estabelecido um parentesco entre a educação de uma criança e o processo civilizatório. Para o autor, mais do que buscar um tipo de homem ideal, educar assemelha-se ao tornar-se homem. Civilizar e educar aparecem em Freud como sinônimos que têm como tarefa determinante o processo de hominização.

Segundo Kupfer (2000), na psicanálise há um alargamento do conceito de educação, uma vez que esta se estende à inserção do bebê na cultura:

o ato de educar está no cerne da visão psicanalítica de sujeito. Pode-se concebê-lo como o ato por meio do qual o Outro primordial se intromete na carne do infans (a criança que ainda não fala), transformando-a em linguagem. É pela educação que um adulto marca seu filho com marcas de desejo. (p. 35)

Nessa concepção de educação, não podemos separar de modo muito claro os campos da psicanálise e da educação, já que ambos estariam referidos ao processo de constituição subjetiva. Nesse sentido, a construção de laços sociais pode ser tomada como efeito do ato educativo, visto que o sujeito pode constituir-se e enlaçar-se ao outro a partir dessas primeiras marcas feitas pelo Outro na tentativa de torná-lo familiar.

Jerusalinsky (2010) afirma que educar seria transmitir uma escritura. "Uma escritura que tenta reproduzir tal e qual ela foi estabelecida. E, nessa tentativa, é fácil

284 Estilos clin., São Paulo, v. 22, n. 2, maio/ago. 2017, 283-298. 
verificá-lo, não há outro resultado senão o constante fracasso" (p. 13). O que se transmite não é o conteúdo em si, não se trata do conteúdo escolar ou do modo de se comportar a mesa. O que se transmite (ou busca-se transmitir) é um signo portador de uma inscrição, é o reconhecimento de uma pertença à cultura, ou seja, trata-se de uma inscrição simbólica. A educação, nessa perspectiva, antes de relacionar-se a um ensino ou aprendizagem, está ligada a uma inscrição que faz seguramente uma amarra, um nó entre o sujeito e a rede de costumes, direitos e leis, modos de gozar, limites e possibilidades próprios do conjunto social simbolizado em cada ato educativo (Jerusalinsky, 2010).

A educação é, portanto, instauradora de realidade, não do real que é dado objetivamente, mas da realidade tecida e construída por cada um, que chamamos de realidade psíquica. No entanto, deve haver uma construção coletiva dessa realidade, uma ficção coletiva para que se possa viver em grupo. A educação visa tornar comum o que nós temos. A tradição é essa ilusão de que falamos a mesma língua e nos entendemos. Tenho que supor que quando digo algo o outro entenderá; e se ele não entender, eu digo de novo, e de novo. Neste processo estou amarrado ao outro, buscando transmitir a escritura a que se referia Jerusalinsky, que é impossível de ser reproduzida. É nesse sentido que compreendemos que a educação, como um ato de fala, é um ato de impossível controle.

\section{Sabe-se sobre a criança?}

A educação pode estar entre os fazeres impossíveis do homem, como afirmou Freud $(1925,1937)$, mas, nem por isso, deixa de acontecer. Muito pelo contrário, foi a partir da tentativa de responder à pergunta sobre como educar que filósofos e educadores se debruçaram ao longo de anos sobre essa tarefa. Como educar uma criança? Como sistematizar um fazer que inevitavelmente deve ocorrer?

É a partir dessas questões que pode ser desenvolvida uma série de prescrições pedagógicas sobre o melhor modo de o professor conduzir seu aluno. $\mathrm{Na}$ tentativa de alcançar esse fim, a pedagogia tem se servido cada vez mais de conhecimentos psicológicos, já que o psicólogo é aquele especialista que sabe sobre o modo como uma criança aprende e como é possível adequar suas capacidades individuais às exigências sociais e pedagógicas. Lajonquière (2009), ao cunhar a expressão discurso (psico)pedagógico hegemônico, analisa esse tipo de discurso caracterizado por uma premissa totalizante que se apoia em um cientificismo psicológico. Segundo o autor, tal tendência atua na contramão do ato educativo, já que favorece a psicologização do cotidiano escolar e se sustenta na tese da adequação entre a intervenção do adulto e as capacidades inatas do aluno. 
Lajonquière defende que a escola apresenta uma tendência a tornar-se antieducativa, como se houvesse uma renúncia do ato de educar em prol dos saberes adquiridos pela ciência em nome da pedagogia. "As ilusões pedagógicas... visam abortar, paradoxalmente, a possibilidade de que aconteçam efeitos educativos ou subjetivantes" (Lajonquière, 2009, p. 22, grifos do autor). Nesse sentido, entendemos que o potente efeito de constituição subjetiva que toda educação carrega torna-se difícil de acontecer quando se está inebriado pela busca do conhecimento psicopedagógico (leia-se: científico).

O autor afirma que, no Brasil, ocorre uma renúncia das possibilidades educativas de maneira semelhante à descrita por Maud Mannoni na França. Isso ocorre pois aqui a demanda educacional revela-se desproporcional para algumas crianças e adolescentes, de tal maneira que não há um "vazio" no qual a criança construa sua demanda e acesse seu desejo de aprender. O que temos é um excesso da exigência de que a criança encarne o ideal do educador, que funciona como um "trator pedagógico", condenando-a à inibição intelectual ou à repetição ecolálica de conteúdos escolares (Lajonquière, 2009).

Ainda segundo Lajonquière, no que se refere às crianças com as ditas "necessidades educativas especiais", atualmente assistimos à consolidação do sistema de cuidados paralelos, sejam eles médicos ou psicopedagógicos, alimentados pelas ilusões cientificistas de tal modo que a criança, sob o mote de criança "incluída", acaba não tendo a oportunidade de se educar - ainda que algumas adquiram automatismos por alguns considerados conquistas educativas. Deste modo, "quanto mais inflacionada está a dimensão psicopedagógica, mais fica comprometida a educativa" (Lajonquière, 2009, p. 25).

É diante desse impasse no processo de subjetivação, inerente ao ato educativo, que nos perguntamos a respeito dos saberes sobre a criança na escola. A quem é atribuído o saber sobre a infância hoje em dia? Os pais vêm sendo destituídos do lugar de quem sabe educar os filhos, já que apenas tem valor o que é cientificamente comprovado. Sendo assim, onde localiza-se o saber? Para refletir a esse

286 Estilos clin., São Paulo, v. 22, n. 2, maio/ago. 2017, 283-298. 
respeito, a seguir abordaremos três atores e seus discursos que circulam no universo escolar e, principalmente, na inclusão escolar: educadores, professores, especialistas (que geralmente atuam cuidados paralelos à escola) e o acompanhante terapêutico.

\section{Educadores e professores}

Transtorno do Déficit de Atenção e Hiperatividade (TDAH), Transtorno Opositor Desafiador (TOD), Transtorno do Espectro Autista (TEA), Dislexia, Distúrbio do Processamento Auditivo Central (DPAC): os diagnósticos presentes no discurso escolar são muitos e já fazem parte do cotidiano. No entanto, nos perguntamos de que modo entram nas escolas e que efeitos produzem. Não raro, vemos coordenadores escolares que solicitam às famílias que investiguem a criança, pois ela apresenta "alguma questão" na leitura, na escrita ou no relacionamento com os colegas. Em seguida, o discurso do neurologista ou psiquiatra entra na escola através de um diagnóstico.

Sabemos da importância que têm tais diagnósticos no universo da saúde (ainda que também ali possam ser objeto de crítica), no entanto, no meio escolar, observamos o efeito negativo que esses saberes podem - falamos de uma possibilidade, e não de uma obrigatoriedade - produzir no trabalho docente. A questão que se coloca é: quem sabe? "Se o médico produziu um diagnóstico sobre aquela criança, certamente saberá mais sobre ela do que eu". Esse é possivelmente o raciocínio do professor, que, ao pensar assim, contribui para a crise diagnóstica na escola, como afirmou Dunker (Informação verbal, 2 de outubro de 2014) ${ }^{1}$. O que ocorre, segundo o psicanalista, é que o professor, diante da avalanche de saberes médicos e psicopedagógicos, se coloca em um lugar de mero funcionário do saber, como se desautorizasse, se destituísse do lugar discursivo do mestre - que é aquele a quem atribuímos o saber. Segundo Guarido (2007):

se por um lado, os profissionais da Educação se veem destituídos de sua possibilidade de ação junto às crianças pela hegemonia do discurso das especialidades; por outro, ao assumir e validar os discursos médico-psicológicos, a pedagogia não deixa de fazer a manutenção dessa mesma prática, desresponsabilizando a escola e culpabilizando as crianças e suas famílias por seus fracassos. (p.157)

Ao se identificar com o discurso hegemônico das especialidades, portanto, o professor se coloca como alguém que simplesmente atua, recuando para o lugar do funcionário da ciência, encarnada pelo médico ou psicopedagogo. Outra possibilidade seria o professor se colocar como detentor de um saber a mais. Nesta segunda posição frente ao discurso das especialidades, o professor se coloca não em contraposição ao 
saber do especialista, mas como portador de um outro saber, o saber de dentro (ou educativo).

Muitos professores escutam as respostas produzidas pelos alunos diante das demandas escolares. Embora haja especialistas que, além do diagnóstico, enviam uma carta prescritiva à escola sobre como a equipe docente deve atuar com aquela criança, ainda assim o professor pode se posicionar nesse debate a sua maneira. Isso significa assumir que a discussão lhe diz respeito. Dunker (2014) defende que não devemos tomar o professor como psicólogo, mas compreender que existe um raciocínio diagnóstico em curso naquele que convive com a criança; um raciocínio que o faz investir mais ou menos, apostar, tolerar, medir etc. Talvez possamos falar na existência de um diagnóstico pedagógico, já que é se perguntando sobre como tem respondido a criança às suas intervenções que o professor pode produzir um saber que diga respeito à educação. Vejamos uma situação em que um diagnóstico pedagógico de um professor entra na cena educativa.

Presenciei, em uma escola particular de São Paulo, um professor de história de Ensino Fundamental - muito envolvido com seu aluno, que "não assistia às suas aulas", "não ficava sentado na cadeira", "não conseguia copiar os conteúdos da lousa", "fazia comentários que não tinham sentido" - que soube produzir um saber sobre seu aluno a partir da relação entre eles. Ao invés de buscar as prescrições dos especialistas - que além do diagnóstico de bipolaridade, já haviam fornecido uma cartilha sobre como atuar com o aluno -, o professor passou a observá-lo e percebeu que, em uma aula em que o assunto era feudalismo, o aluno havia feito vários desenhos em seu caderno sobre esse conteúdo. A partir disso, houve uma aposta de que ali poderia haver um vínculo interessante entre o aluno e o conteúdo da disciplina. O produto final de tal aposta foi um trabalho de tirinhas relacionado ao feudalismo que uma criança "bipolar", pouco alfabetizada, foi capaz de produzir e, mais do que isso, de despertar sua curiosidade e seu interesse para aquele trabalho, a partir de uma intervenção de um professor que se propôs a uma escuta.

Mas também há não saberes e angústias. Há o professor que não sabe como lidar com o aluno que não olha para ele ou não responde as suas perguntas. Esse educador se questiona sobre como seria o melhor modo de ensinar aquela criança que "deveria", mas ainda não sabe ler; ou como fazer entrar na classe aquele garoto que insiste em ficar de fora. Esses são professores que assumem um não saber, se colocam em dúvida e, por um breve momento, suportam que algo falte. Segundo Lerner (2013), “o não saber dos professores diante da inclusão é tomado como incapacidade e não como ponto de partida para a construção de um trabalho com a criança” (p. 103). Este não saber, em geral, não é visto como condição de trabalho para que algo da ordem do singular possa surgir, mas como algo a ser eliminado, dado que insuficiente frente ao ideal (p. 150).

288 Estilos clin., São Paulo, v. 22, n. 2, maio/ago. 2017, 283-298. 
Aqui abriremos um breve parêntese para distinguir a educação ideal do ideal de educação, a partir das noções freudianas de Eu Ideal e Ideal de Eu. Grosso modo, segundo Petri (2003):

A educação ideal é um mandato imaginário, que pretende ter respostas para tudo, não há espaço para o imprevisto, para a criação, enfim para o desejo, quem recebe o mandato fica no lugar de objeto que deve completar o Outro mandante. O ideal de uma educação é de ordem simbólica, articula uma demanda que é enigmática, tem proibição, abrindo a possibilidade para o desejo, para o imprevisto, para o improviso, para o surgimento do desejo. (p. 25)

Desse modo, ao assumir a educação ideal, colocando os ideais de aluno e de professor como um mandato imaginário a ser alcançado, estaremos sempre na angústia da falta a ser preenchida - por mais saberes científicos e prescritivos que existam. Se, por outro lado, assumirmos a falta como o espaço do imprevisto, da surpresa, talvez possamos nos aproximar da precipitação do desejo que mais se relaciona com a concepção de educação que trouxemos anteriormente. Talvez, naquele momento, o aluno não olhe nos meus olhos, e pode ser aceitável que o estudante ainda não saiba ler ou que o garoto não entre na sala de aula, isso se nos pautarmos pela ética da diferença, que propõe a singularidade como parâmetro. Deixando de lado o "mas ele deveria...", talvez consigamos possibilitar àquela criança ser o que puder naquele momento e, assim, possamos valorizar o caminho que ela tece ao ser tensionada por esse ideal.

\section{Especialistas}

Maud Mannoni, ao criar a École expérimentale de Bonneuil-sur-Marne, se propôs combater o excesso de tratamento que acabava colocando a criança em um lugar de objeto, de alienação. Para Mannoni, o saber está na própria criança psicótica, e, portanto, o tratamento 
seria justamente sair desse lugar objetalizante, simplesmente vivendo em um lugar de vida. Neste sentido, ela propõe que a desalienação é por si só terapêutica, já que a mudança do lugar que a criança ocupa em relação aos adultos modifica o saber deles em relação à criança.

O que observamos hoje em muitas crianças, mas principalmente nas ditas com "necessidades educativas especiais", é a existência de uma rede de cuidados médicos, psicológicos e pedagógicos paralelos à escola na qual corre-se o risco de colocá-las no lugar objetalizante descrito por Mannoni. $\mathrm{E}$ as escolas, nesse processo, acabam atuando de maneira muito permeável ao discurso científico das especialidades. Sobre isso, Guarido (2007) afirma que:

com a hegemonia do discurso psiquiátrico sobre os sofrimentos e as disfunções comportamentais e cognitivas das crianças, vemos que a Educação encontra-se mais uma vez, ou mais intensamente, atravessada pelo discurso especialista. Seria preciso resgatar e exercer algo do domínio do ato educativo nas escolas sem que este tivesse antes que estar vinculado à observação de especialistas ou à orientação destes, permitindo que as crianças tivessem ao menos um pertencimento social não atravessado por suas denominações ou rotulações diagnósticas. Esta talvez seja uma das grandes possibilidades que a Educação Inclusiva permite às crianças que estiveram até então fora da escola: estar na escola resgata um lugar social não conferido até pouco tempo atrás às crianças em grave sofrimento psíquico. (p. 157)
A aposta que faz Guarido é de que, através da inclusão escolar, a criança ocupe um lugar diferente do lugar de paciente que possui um diagnóstico médico; no entanto, sabemos da dificuldade de isso ocorrer nos dias atuais. Eis um importante paradoxo da inclusão: se, por um lado, se pretende proporcionar à criança na escola um lugar para além dos rótulos diagnósticos, promovendo "um lugar de vida", como sugere Mannoni, onde ela pode ser simplesmente aluno, por outro, vemos a crescente entrada do discurso médico e dos especialistas, no qual se localiza a criança novamente no lugar daquele que não sabe sobre si, lugar de objeto de estudo da ciência. E neste jogo de saber, não só a criança corre o risco de ocupar esse lugar objetalizante; também o professor, como descrevemos anteriormente, pode se desautorizar ao ver-se reduzido a um funcionário do saber científico.

Entendemos que há duas maneiras distintas do discurso do especialista estar presente nas escolas: a primeira seria através da sobreposição de seu saber em detrimento do saber dos professores, e a segunda, através do diálogo com os professores. É comum que um mesmo discurso, encarnado na figura de um especialista, possa transitar entre essas duas posições. O que o determinará é o uso clínico que o profissional faz de seu saber, dependendo, portanto, da posição em que se coloca frente aos outros saberes escolares. 
O discurso do especialista sobreposto ao discurso escolar tem um parentesco com o trabalho desenvolvido por Itard com Victor de Aveyron ${ }^{2}$ e seus contemporâneos. São tratamentos descritos como médico-pedagógicos que se realizavam com os chamados idiotas - portadores de retardo, que ainda não possuía um estatuto de doença mental. Itard era médico especialista na educação de surdos-mudos e tinha uma teoria que seu aluno deveria ilustrar. Havia, nesse sentido, pouca escuta para o que não fosse parte do treinamento proposto pelo médico. Segundo Guarido (2007):

O marco empreendido por Itard é então de conjugar medicina e pedagogia, dando lugar à constituição de um saber médico sobre a criança considerada idiota, saber esse que se nomeará pouco depois como psiquiatria da criança ou psiquiatria infantil e que, além disso, influenciará a formação da Educação Especial. (p. 155)

Em casos como esse, nota-se que a posição do especialista é valorizada como detentora de um saber sobre a criança. O especialista apela ao saber científico fazendo com que os profissionais e a criança estejam submetidos ao discurso universitário (Lerner, 2013). Em suma, conforme formulado por Lacan, o que o discurso universitário busca promover é um saber total sobre o outro, o objeto, a partir de uma pergunta a-subjetiva, isto é, deslocada da ordem do singular. Temos a pergunta de um professor acerca de um aluno, e se o especialista se propõe a respondê-la e a tamponar essa falta, só restará ao professor executá-la. O que se exacerba são as certezas advindas das técnicas, isto é, ao "deve-se" ou "não se deve" fazer, deixando pouco espaço às interrogações.

E da perspectiva da criança, vemos que pais, professores, coordenadores e os próprios especialistas acabam por tomá-la como um aparelho biológico que falha. Fonoaudiólogos cuidam de sua fala, o psicólogo de suas emoções, o psicopedagogo de sua inteligência, e assim se despedaça a criança em partes, ignorando a dimensão de sujeito e sua história particular com sua deficiência ou transtorno psíquico. A criança se torna objeto de cuidados: "é de sua inteligência que se trata, de seus movimentos, de sua audição, de sua fala. Não lhe perguntam o que ela quer, com o que sonha, o que sente, qual é sua história, quais poderiam ser seus projetos de vida" (Bernardino, 2007, p. 52).

Esse jogo de saberes sobre a criança, ainda que realizado de modo paralelo à escola, volta a surgir no meio escolar principalmente na forma de respostas e conhecimentos científicos capazes de trazer a medida exata da ação dos educadores. O contato com a criança passa então a ser mediado pel'A criança - aquela descrita nos livros e manuais dos especialistas. A esse respeito, Voltolini (2011) nos lembra o significado da palavra compreender: 
Quer dizer, "prender" implica um ato de aprisionar, de cativar o outro, o que resulta sempre num certo apagamento do que o outro diz a fim de que o que eu sei dele - e que me reafirma narcisicamente - não se abale. Donde um paradoxo funesto para o educador: quanto mais aumenta esse gênero de conhecimento sobre a criança, menos apto ele está a escutar o que ela diz e, consequentemente, mais longe de tomar uma decisão em sintonia com o que exige cada situação envolvendo a criança. (p.44)

Importante ressaltar que a relação entre o discurso das especialidades e outros discursos escolares depende não só da posição que é tomada pelo próprio especialista, mas também pelo modo como a própria equipe escolar toma esse discurso com valor de verdade. $\mathrm{Ou}$ seja, assumir que existe uma verdade sobre aquela criança é diferente de tomar várias verdades (portanto, vários saberes, inclusive o do próprio aluno) como produtores daquela realidade.

Assim, entendemos que a segunda possibilidade de o discurso das especialidades aparecer na escola é por meio do reconhecimento das várias verdades. Trata-se não de dar orientações e prescrições aos professores, mas de conduzir as questões de tal maneira que a equipe docente se interrogue sobre suas práticas e possa fazer algo de produtivo e criativo com as próprias perguntas e inquietações - perguntas como "o que essa criança queria dizer? O que será que ela sabe? O que já tentei ensinar? Como foi? Por que será?" etc. Trata-se, justamente, de abster-se do lugar de especialista. Desde essa posição discursiva, busca-se promover uma passagem da queixa para a interrogação, de modo que ocorra um deslocamento do lugar ocupado pelo aluno na produção discursiva do professor. Com isso, há a emergência de um espaço para que o professor e o próprio aluno produzam saberes sobre si e seu fazer.

É deste modo que defendemos a possibilidade de o profissional externo à escola estar presente na instituição em um lugar não-todo, isto é, "contando com um campo de conhecimento específico, mas sem que ele se sobreponha aos saberes construídos na relação singular da professora com seu aluno" (Lerner, 2013, p. 117). Assim,

292 Estilos clin., São Paulo, v. 22, n. 2, maio/ago. 2017, 283-298. 
sem tamponar o não saber contido no enigma do educar, é possível produzir saberes que sejam não universais e, por isso mesmo, educativos, já que supõem os sujeitos em jogo no ato. Algo que, orientados pela psicanálise, procuramos fazer a partir da clínica do acompanhamento terapêutico nas escolas.

\section{Acompanhante terapêutico escolar}

O acompanhante terapêutico na escola, em um primeiro momento, pode ser convocado desde o lugar de especialista. Pode ser visto pela equipe escolar como aquele que possui o saber total sobre a criança, sendo capaz de responder a todas as perguntas dos professores ou até fazê-las por eles. Se isso ocorrer, será necessário que o profissional escute a demanda escolar, de modo a propor outra forma de trabalho, isto é, outra maneira de saber. O saber, nesta perspectiva, está naquele que articula a demanda. Vejamos uma breve cena da entrada de um acompanhante terapêutico em uma escola.

Chegando no primeiro dia na escola para acompanhar uma criança de 5 anos. Em reunião com a professora e a diretora da escola, a primeira diz: "nossa, que bom que você veio! Nós estávamos desesperados para que algum expert no assunto pudesse vir nos ajudar e dizer como trabalhar com Breno ${ }^{3}$. Ele nos dá muito trabalho e não fui formada para trabalhar com esse tipo de criança".

Fica evidente nessa curta cena o saber científico sobreposto ao educativo, ou seja, "o tipo de criança" é colocado na dianteira do trabalho educativo. O saber aqui é atribuído ao acompanhante terapêutico que, supostamente, portaria um discurso científico sobre o aluno. Nessa perspectiva, tanto a criança quanto o professor estariam localizados como objetos do discurso científico, o que tem como consequência uma impossibilidade da transmissão educativa que supõe sujeitos em ato. 
Orientado pela psicanálise, dizemos que há uma posição ética do acompanhante terapêutico de suposição de sujeito. Ainda que trabalhe com crianças psicóticas ou autistas em que o que aparece de sujeito é incipiente, dizemos que há uma crença no sujeito, uma aparição precária, porém possível, que só pode ocorrer caso o profissional se coloque ao lado da criança e possa construir um saber com ela, e não sobre ela. Retomando a definição de "compreensão" que apresentamos anteriormente, diremos que o acompanhante terapêutico nada compreende de seu acompanhado, é incapaz de prendê-lo em um saber, visto que este localiza-se justamente do outro lado, isto é, do lado do sujeito.

Breno, no início do acompanhamento terapêutico, costumava, durante o horário do brinquedo, por qualquer motivo (e às vezes, sem nenhum), bater nos colegas. Isso começou a tornar-se cada vez mais frequente. Fui reparando que sempre havia um brinquedo no meio da briga, mas que não necessariamente Breno tentava pegar da mão da criança ou demonstrava qualquer interesse no objeto. Como uma tentativa de dar sentido àqueles seus atos que eram lidos como incompreensíveis pela professora, disse num determinado dia a uma criança que Breno havia feito aquilo pois desejava brincar com o brinquedo que o garoto tinha em mãos, mas que não soube dizê-lo (importante lembrar que nesse momento ele falava poucas palavras e muito incompreensíveis). Isso teve um efeito em Breno e nos seus colegas, que aos poucos foram me ajudando a atribuir sentidos para seus atos violentos.
Mais importante que o sentido atribuído ao ato da criança é a presença dele. Ou seja, não importa se de fato a criança quis dizer aquilo. $\mathrm{O}$ valioso dessa intervenção é que haja um sentido. O sentido tem uma inscrição no laço e coloca a criança em contato com os outros na cena. Que seja para as crianças brigarem de volta dizendo "Breno! Não é assim que você pede o brinquedo!" não importa. Melhor isso do que os atos bizarros e sem sentido descritos no primeiro momento pela professora. Essa intervenção guarda relações com o choro do bebê: de início não há nada inato que signifique aquele choro (pode ser fome, sede, cólica?), a mãe não sabe, mas precisa supor um sentido no choro de seu filho inscrevendo-o na linguagem. “Ele quis dizer isso!": essa suposição é constituinte.

$\mathrm{O}$ acompanhante terapêutico age na escola de maneira a não permitir que o discurso pedagógico, dotado de inevitável mestria, seja excessivo e totalitário para a criança. Esse profissional, por vir de fora da escola, tem a possibilidade de interrogar os ideais e mostrar o impossível da tarefa de educar ao mesmo tempo em que trabalha em parceria com os atores escolares na construção de um lugar possível e suportável para a criança na escola.

Nesse sentido, o trabalho do acompanhante terapêutico será o de construir, junto com a criança e a partir das pistas que ela fornece, um novo saber sobre ela própria, algo que diz respeito àquele sujeito singular e não 
se relaciona com os saberes científicos universais. É desse modo que justificamos que o trabalho do acompanhante terapêutico é o de um fazer avesso ao saber sobre a criança: o saber está na criança, e não no outro, há ali um saber opaco e esfumaçado que esse profissional descobrirá junto com ela. $\mathrm{O}$ acompanhante terapêutico coloca-se em uma posição de não saber para que possa emergir um saber do pequeno sujeito. A esse respeito, a seguir apresentamos mais uma cena de acompanhamento terapêutico.

Início da manhã, todas as crianças em roda escutando a professora explicar a rotina. Eduardo tinha três anos e ainda não falava. Era-lhe muito custoso suportar durante muito tempo os momentos de roda em que a palavra se impunha. Sua saída foi ir para o meio da roda; senta, olha em volta e ali permanece. A professora lhe orienta para que volte ao seu lugar, mas Eduardo não o faz. Então, ela me olha com um pedido de ajuda nos olhos. Eu, como acompanhante terapêutica de Eduardo, poderia nesse momento responder essa demanda e incentivá-lo a sentar-se no lugar que lhe fora atribuído (na roda). O que fiz? Nada. Sorri para ela e a encorajei a prosseguir com a rotina, suportando que Eduardo estivesse fora da roda. Eduardo permaneceu durante algum tempo naquela posição. Chegou a ir para o "seu lugar", mas depois voltou para o meio da roda e, assim, lidava como podia com a demanda da professora.

Minha atitude foi a de não ajudar a promover o ideal de aluno naquele momento - a criança sentada adequadamente na roda - e, assim, deixar um espaço para que Eduardo se colocasse como sujeito destinatário da demanda da professora. Com isso, eu pretendia marcar uma diferença: Eduardo não era igual às outras crianças (não naquele momento) e foi importante que isso fosse suportado pela professora para que o garoto tivesse seu tempo. Aos poucos, Eduardo foi percebendo que podia convocar o olhar do outro de outras maneiras, ainda que não soubesse falar. Entretanto, naquele momento, era o recurso que tinha à mão, e não impor a ele o ideal de aluno possibilitou que ele pudesse, a seu tempo, fazer essa descoberta.

Curvado em uma posição de ignorância, o acompanhante terapêutico deve estar atento aos movimentos das crianças, ser capaz acompanhar suas idas e vindas pela escola, suas descobertas e suas frustrações, curioso para aprender sem muito compreender. Essa posição sustentada em um não saber, além de ser uma possibilidade de vínculo com uma criança psicótica ou autista, comporta também uma relação com os professores na qual algo de criativo pode surgir a partir do momento em que eles também são colocados no jogo do enigma do ensinar-aprender.

Essa posição sustentada em um não saber não significa, diante de um impasse com a criança, enunciar a dúvida ou o silêncio, mas sustentar em ato o papel de analista. Ou seja, sustentar a demanda que vem da equipe escolar em relação ao enigma da criança, a fim de que uma elaboração feita a partir da dúvida do professor possa ser colocada. Alícia me mostrou que eu não sabia sobre ela e isso teve efeitos importantes para a sua relação com as professoras. 
Segundo dia de acompanhamento terapêutico, Alícia em crise, chorando muito, porque queria pegar um presente que uma colega de sala havia ganhado e as professoras não deixaram, dizendo que não lhe pertencia. As professoras continham fisicamente Alícia enquanto ela agitava seu corpo, se batia, batia nos outros, gritava e se jogava no chão. Perguntei como isso havia começado, e as professoras me responderam que foi quando disseram a Alícia que ela não podia pegar o presente, mas não sabiam se ela havia compreendido.

Depois de dizerem a Alícia que ela não podia pegar o presente da colega, as professoras começaram a sugerir à menina que fosse brincar no parque e a oferecer uma série de outros estímulos e brinquedos para ela. Mas não tinha jeito: Alícia não queria outra coisa a não ser o pacote de presente cor de rosa. "Será que ela entendeu que não pode? Por que ela quer o pacote?", perguntava a professora. "Pega a massinha ali do lado, veja se ela se interessa", respondia a professora auxiliar. Tentei conversar com Alícia por alguns instantes, mas ela não me respondia, não dizia nenhuma palavra além dos gritos que já estava dando há alguns minutos. Sugeri então que elas soltassem Alícia e observassem o que ela faria, pois não sabíamos nem se ela havia entendido o porquê de não poder mexer no pacote cor de rosa, nem o que ela queria fazer com ele. Já sem muitas opções, as professoras aderiram à minha sugestão, e então vimos Alícia agarrar o pacote cor de rosa e se deitar no chão, tranquila, sem abrir o presente da colega ou rasgá-lo. Passados alguns instantes assim, Alícia se levantou e saiu correndo para brincar no parque. Muitas perguntas, nenhuma resposta.
Sustentamos uma posição de não saber sobre a criança, sobre seu comportamento. Apenas a acompanhei nesse momento de crise e deixei que as perguntas permanecessem - "o que ela quer com esse pacote cor-de-rosa?", "será que ela nos compreende?" -, não sendo ofuscadas e eliminadas rapidamente por outros brinquedos ou distrativos. Essa cena voltou a acontecer. Uma vez com um shampoo, outra com um martelo de verdade. Várias vezes foi necessário, junto à equipe de professoras, sustentar um não para Alícia, mas sem eliminar as dúvidas. Depois desse episódio, durante o tempo de acompanhamento, a professora auxiliar, diante de um impasse como esse, vinha me contar e descrever exatamente o ocorrido, para que pudéssemos pensar juntas que pistas Alícia estava nos dando. Tamponar a dúvida com outros brinquedos ou distrativos não lhe parecia mais o fundamental. Abriu-se uma escuta para Alícia.

Recolocar a dimensão clínica do ato educativo talvez seja uma tarefa ética da psicanálise quando tratamos da inclusão escolar. Clínica no sentido de inclinar-se para escutar o outro de modo que se constitua um saber a partir do singular. Onde há práticas e técnicas universalizantes, poder ancorar um saber da ordem do singular é uma tarefa cara à psicanálise, e que propomos como possível a partir da clínica do acompanhamento terapêutico na escola. 
CAN ANYONE KNOW ABOUT THE CHILD? THER APEUTIC ACCOMPANIMENT AND INCLUSIVE EDUCATION

ABSTRACT

This article aims to argue about the practice of therapeutic accompaniment as a clinical modality of support for school inclusion through the formulation on the therapeutic companion's (non) knowledge, for those who work guided by psychoanalysis. Through clinical vignettes, we will approach three actors and their speeches that circulate in school inclusion's universe: educators, specialists and finally the therapeutic companion.

Index terms: inclusive education; psychoanalysis; education; therapeutic accompaniment; knowledge.

\section{¿SE SABE SOBRE EL NIÑO? ACOMPAÑ AMIENTO \\ TERAPÉUTICO Y EDUCACIÓN INCLUSIVA}

\section{RESUMEN}

En este trabajo se pretende pensar la práctica de acompañamiento terapéutico como una modalidad de apoyo a la inclusión escolar desde una formulación del (no) saber del acompañante terapéutico que trabaja en la escuela guiado por el psicoanálisis. A través de viñetas clínicas, trataremos trés actores y sus discursos que circulan en el universo de la inclusión escolar: educadores, expertos y, finalmente, el acompañante terapéutico.

Palabras clave: educación inclusiva; psicoanálisis; educación; acompañamiento terapêtico; saber.

\section{REFERÊNCIAS}

Arendt, H. (2011). Entre o passado e o futuro. São Paulo, SP: Perspectiva (trabalho original publicado em 1954).

Bernardino, L. (2007). A contribuição da psicanálise para a atuação no campo da educação especial. Estilos da Clinica, 12(22), 48-67. doi: http://dx.doi.org/10.11606/issn.1981-1624.v12i22p48-67

Freud, S. (1996). Prefácio a "Juventude Desorientada”, de Aichhorn. Edição standard brasileira das obras psicológicas completas de Sigmund Freud (J. Salomão, trad., Vol. 19, pp. 303-308). Rio de Janeiro, RJ: Imago (trabalho original publicado em 1925)

Freud, S. (1996). Análise terminável e interminável. In S. Freud, Edição standard brasileira das obras psicológicas completas de Sigmund Freud (J. Salomáo, trad., Vol. 23, pp. 223-270). Rio de Janeiro, RJ: Imago(trabalho original publicado em 1937) 
Guarido, R. (2007). A medicalização do sofrimento psíquico: considerações sobre o discurso psiquiátrico e seus efeitos na Educação. Educação e Pesquisa: Revista da Faculdade de Educação da USP, 33(1), 151-161. doi: http://dx.doi.org/10.1590/S1517-97022007000100010

Kupfer, M. C. M. (2000). Educação para o futuro: psicanálise e educação. São Paulo, SP: Escuta.

Jerusalinsky, A. (2010). Apesar de você, amanhã há de ser outro dia: dialética da demanda e do desejo na educação. In C. Calligaris et alli (Orgs.), Educa-se uma criança? (pp.13-23). Porto Alegre, RS: Editora Artes e Ofícios.

Lajonquière, L. (2009) Infância e ilusão (psico)pedagógica. Escritos de psicanálise e educação. Petrópolis, RJ: Vozes.

Lerner, A. B. C. (2013) Consequências éticas da leitura psicanalitica dos quatro discursos para a educação inclusiva. Tese de Doutorado em Educação, Faculdade de Educação, Universidade de São Paulo, São Paulo.

Petri, R. (2003) Psicanálise e educação no tratamento da psicose infantil: quatro experiências institucionais. São Paulo, SP: Annablume/ Fapesp

Voltolini, R. (2011). Educação e psicanálise. Rio de Janeiro, RJ: Zahar.

\section{NOTAS}

1. Na I Jornada de Fonoaudiologia, Educação e Psicanálise, que ocorreu no dia 2 de outubro de 2014, no Instituto de Psicologia (IP) da USP.

2. Victor, mais conhecido como o selvagem de Aveyron, foi encontrado no ano de $1800 \mathrm{em}$ uma floresta no sul da França. O garoto com cerca de 11 anos de idade, que parecia um selvagem, foi enviado a um instituto de surdos-mudos em Paris onde encontrou o jovem médico Itard, que se encarregou diretamente de sua educaçáo moral e intelectual, com o propósito de torná-lo apto ao convívio social. Tratou-se de um trabalho menos relacionado ao que hoje entendemos como educação e mais semelhante a um treinamento ou adestramento.

3. Os nomes utilizados nas vinhetas clínicas são fictícios.

spedolenara@gmail.com

Rua Almirante Brasil, 243/ 151M 03164-120 - São Paulo - SP - Brasil. 